\title{
FERRAMENTAS DE BENCHMARKING COMO DIFERENCIAL COMPETITIVO EM EMPRESAS DE FASTFOOD NA CIDADE DE NATAL - RN
}

\author{
H. R. HEKIS ${ }^{1}$, R. P. SOUZA, D. D. O. MEDEIROS, I. B. F. SILVA e T. M. D. BORGES \\ Departamento Engenharia de Produção - Universidade Federal do Rio Grande do Norte \\ hekis1963@gmail.com ${ }^{1}$
}

Artigo submetido em setembro/2012 e aceito em julho/2013

\section{RESUMO}

É notório, na contemporaneidade, o aumento da procura pelos produtos disponibilizados pelas redes de fastfood, gerando consequentemente o crescimento econômico das organizações do setor. Logo esse trabalho objetiva demonstrar o sistema de monitoramento de arranjos produtivos - SIMAP as empresas estudadas para que estas possam vislumbrar novas atividades de gestão com o intuito de ter um diferencial competitivo. Para alcançar esse objetivo utilizou-se a metodologia exploratória explicativa, com estudo de caso nas empresas Pittsburg e McDonald's na cidade de Natal-RN, obtendo-se as informações através de questionário semiestruturado. Analisando-se os dados, percebeu-se que as empresas estudadas, encontram-se acima da média das empresas do setor cadastradas no SIMAP. Em comparação cruzada entre as empresas estudadas, observou-se que a empresa Pittsburg possui pontos a aperfeiçoar, nos diversos indicadores de gestão, em especial no indicador sistema de gestão integrada, no qual essa empresa ficou abaixo de $25 \%$. Observou-se também que em relação à gestão financeira, a empresa Pittsburg esta melhor qualificada perante sua concorrente McDonald's. Ficou evidenciado que as empresas estudadas estão em conformidade com os requisitos mínimos exigidos pelos seus clientes.

PALAVRAS-CHAVE: Arranjo Produtivo Local - APL, Benchmarking, SIMAP, Fastfood.

\section{TOOLS OF BENCHMARKING TO START A COMPETITIVE DIFFERENCIAL IN FASTFOOD COMPANIES IN THE NATAL- BRAZIL}

\section{ABSTRACT}

It is notorious, in contemporary times, the increased demand for the products made available by fastfood chains, thereby generating economic growth sector organizations. Therefore this paper aims to demonstrate the Sistema de Monitoramento de Arranjos Produtivos SIMAP for the companies studied so that they can envision new management activities in order to have a competitive edge. To achieve this we used the exploratory explanatory methodology, with case study companies in Pittsburg and McDonald's in the city of Natal, RN, obtaining information through semistructured survey. Analyzing the data, it was found that the studied companies, are above the average of the sector companies registered in SIMAP. In crosscomparison between the companies studied, it was observed that the company has Pittsburg points to improve in several management indicators, in particular indicator integrated management system, in which the company was below $25 \%$. It was also observed that in relation to financial management, the company best qualified Pittsburg this before your competitor McDonald's. It was demonstrated that the studied companies are in compliance with the minimum requirements set by its customers.

KEYWORDS: Cluster, Benchmarking, SIMAP, Fastfood. 


\section{FERRAMENTAS DE BENCHMARKING COMO DIFERENCIAL COMPETITIVO EM EMPRESAS DE FASTFOOD NA CIDADE DE NATAL-RN}

\section{INTRODUÇÃO}

Na contemporaneidade à ocupação do tempo com o trabalho e os deveres sociais tornaram-se cada vez mais comuns. A falta de tempo aliado com o baixo custo da refeição tem atraído cada vez mais consumidores para a alimentação rápida - fastfood. (PAULINO, 2012).

A primeira rede de fastfood no Brasil iniciou suas atividades na década de 1950, sendo a rede de lanchonetes Bob's (GARCIA e FERNANDES, 2010). Redes internacionais começaram a direcionar investimento para Brasil na década de 70, sendo a primeira e mundialmente conhecida, McDonald's. Desde então, novas redes se inseriram no país, sendo as principais redes alocadas no Brasil atualmente: Subway, McDonald's, Habib's, Giraffas e Bob's.

O estudo tem como objetivo geral demonstrar o Sistema de Monitoramento de Arranjos Produtivos - SIMAP as empresas estudadas para que estas possam vislumbrar novas atividades de gestão com o intuito de ter um diferencial competitivo. Associado ao objetivo geral o artigo pretende discutir os seguintes objetivos específicos: suprir a lacuna decorrente da ausência de informações referente à cadeia produtiva de alimentos e bebidas no estado do Rio Grande do Norte; comparar os resultados das duas empresas analisadas, fazendo análise comparativa entre elas e entre as empresas cadastradas no SIMAP na cadeia produtiva em estudo.

O problema de pesquisa a ser avaliado, consiste em avaliar os indicadores de gestão de duas empresas da cadeia produtiva de alimentos e bebidas, sendo a primeira atuando mundialmente e a segunda com foco local.

O Estado do Rio Grande do Norte tem grande parte da sua receita oriunda do turismo, assim este trabalho possibilitará o conhecimento detalhado da cadeia produtiva em estudo, visando dar subsídios de informações ao setor, criando diferenciais competitivos as empresas interessadas.

O artigo esta estruturado em seis seções. A seção 2 apresenta síntese da discussão teórica dos temas abordados. A seção 3 apresenta os aspectos metodológicos. As seções 4 e 5 apresentam estudo de caso das empresas Pittsburg e McDonald's e os resultados alcançados, respectivamente. E por fim a seção 6 traz as conclusões, limitações e recomendações para futuros trabalhos.

\section{REFERENCIAL TEÓRICO}

O termo Arranjo Produtivo Local (APLs), vem sendo utilizado recentemente e foi tratado por vários autores como Enright (1999), Porter (1999), Amato Neto (2009), entre outros. Porém para realização da atual pesquisa fixou-se nos conceitos mais atuais, já que essas aglomerações sempre estão em processo de mudança. Dessa forma, para melhor conceituar APLs, buscaram-se as definições nas principais organizações brasileiras de referência, sendo definidas pelo SEBRAE e o BNDES.

Iniciando pela definição do SEBRAE (AQUINO e PINHEIRO, 2006) o qual define APL como: ...aglomerações de empresas, localizadas em um mesmo território, que apresentam especialização produtiva e mantém algum vínculo de articulação, interação, cooperação e aprendizagem entre si e com outros atores locais, tais como: governo, associações empresariais, instituições de crédito, ensino e pesquisa. 
Para o Banco Nacional de Desenvolvimento Econômico e Social - BNDES (BNDES, 2010), tem-se que APL's são:

\begin{abstract}
...uma concentração geográfica de empresas e instituições que se relacionam em um setor particular. Incluem, em geral, fornecedores especializados, universidades, associações de classe, instituições governamentais e outras organizações que proveem educação, informação, conhecimento e/ou apoio técnico e entretenimento.
\end{abstract}

Para monitorar uma APL se faz necessário um sistema que de suporte e subsídios para organização das informações, assim o Sistema de Monitoramento de Arranjos Produtivos SIMAP traz a possibilidade desse suporte.

\title{
Sistema de Monitoramento de Arranjos Produtivos - SIMAP
}

Benchmarking é a busca das melhores práticas nas empresas que conduzem ao desempenho superior, sendo visto como um processo positivo e proativo por meio do qual uma empresa pode verificar como uma outra realiza uma função específica a fim de melhorar o seu desempenho (CAMP, 1998). Gariba Junior (2005, p.43) ressalta que benchmarking é:

[...] um procedimento de pesquisa, contínuo e sistemático, pelo qual se realizam comparações entre organizações, objetos ou atividades, criando-se um padrão de referencia. A técnica de benchmarking visa, portanto, à procura de pontos de referência que comparem o desempenho com a concorrência, com o objetivo de melhorar o rendimento naquele aspecto que se quer medir. $O$ benchmarking sugere um processo estruturado de identificação daquilo que se deseja aperfeiçoar, um processo de investigação de oportunidades de melhoria interna e um processo de aprendizagem, uma vez que não se trata de aplicar nada diretamente, mas sim adaptar as melhores práticas do processo à mentalidade e cultura da própria empresa.

O benchmarking tem como característica principal não ser um evento único, mas uma ação contínua (ARAÚJO 2001), permitindo vislumbrar oportunidades e ameaças competitivas, constituindo a excelência, com a utilização de todo um trabalho intelectual acumulado por outras organizações evitando erros e armadilhas de percursos (GARIBA JUNIOR, 2005).

O SIMAP é considerado uma ferramenta de benchmarking e tem como objetivo acompanhar o desenvolvimento de empresas, de elos e de cadeias produtivas dos principais setores do país (OBSERVATÓRIO TECNOLÓGICO, 2012). Desta maneira, todos os interessados no desenvolvimento do setor, passam a colaborar entre si disponibilizando informações sobre desempenho estratégico, tecnologias de gestão, de processos e de produto direcionando ações e esforços para a competitividade sistêmica (ALBERTIN et al., 2010).

As informações de cada empresa são de natureza sigilosa, e são utilizadas apenas como parâmetros estatísticos de comparação entre si. A participação neste sistema permite que a empresa compare o seu desempenho com outras empresas do setor de atuação, ou em outro setor que queira atuar. As informações permitem apontar que tecnologias estão se destacando em setores específicos, ou mesmo, técnicas e métodos que estão deixando de ser utilizadas.

Mas sua implantação e acompanhamento é uma atividade complexa, devido a necessidade de se observar todo um sistema de empresas, e não mais uma única empresa isolada. Tal sistema imerso num mercado econômico extremamente dinâmico exige um 
monitoramento constante que informe os gargalos e restrições tecnológicos de forma cooperativa e colaborativa a partir de critérios (indicadores) previamente definidos (OBSERVATÓRIO TECNOLÓGICO, 2012).

O SIMAP propicia e acelera o desenvolvimento de novas formas de geração, tratamento e distribuição da informação. A informação, o conhecimento, a inovação e a educação continuada configuram-se hoje como temas centrais dos debates internacionais, uma vez que a formação de vantagens competitivas sustentáveis dos tempos (ALVARENGA NETO, 2005). Os critérios de desempenho avaliados nas empresas através da ferramenta SIMAP, são apresentados na Figura 1.

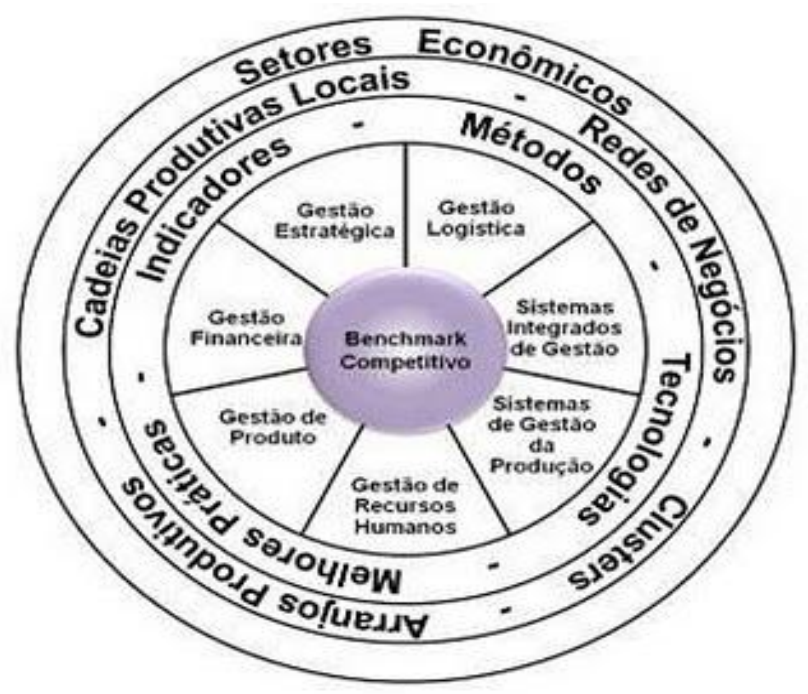

Figura 1: Abrangência do SIMAP. Fonte: adaptado de JOHNSON et al., 2010

O SIMAP aborda sete critérios de desempenho que são utilizados como base para a ferramenta de benchmarking. A descrição de cada critério é visualizada no Apêndice $A$. Esse sistema também tem a capacidade de auxiliar as empresas na entrada de dados e avaliação da organização em comparação com as demais. O modelo de avaliação de empresas se baseia no nível de aplicação das ferramentas para monitorar o desempenho das empresas pesquisadas sob a ótica de gestão. A avaliação do sistema estabelece os níveis de avaliação 0, 25, 50, 75 e 100 e as respectivas condições para que a empresa situe-se ou enquadre-se em cada nível (Apêndice $A$ ).

Com os dados inseridos no SIMAP, relatórios são gerados possibilitando as empresas verificarem sua situação perante as outras empresas cadastradas no sistema. Assim as empresas participantes podem verificar seus pontos fortes e fracos.

\section{Gestão da Produção}

Sistema de produção é um sistema de operações e atividades que possuem uma relação entre si e que estejam envolvidas na fabricação de algum bem ou serviços (MOREIRA, 2000).

Para Slack (2009) gestão da produção refere-se à atividade de gerenciar recursos destinados a produção, assim como disponibilizar bens e serviços para esta. Este autor defende que administrar a produção compreende gerir todas as atividades que promovam a satisfação do cliente, incluindo as tarefas de compra aos fornecedores até a entrega aos consumidores finais.

Certamente, a gestão da produção é considerada uma das três áreas centrais de uma organização, juntamente com o marketing e o desenvolvimento de produtos. Possuir habilidade 
em administrar a produtividade de uma empresa de forma eficiente é um desafio para o gestor. Uma boa gerência de produção possui inúmeras vantagens, podendo reduzir custos, aumentar as receitas, reduzir o capital empregado e consequentemente gerar maior satisfação dos clientes. (QUEIROZ et. al., 2010; HEKIS et. al., 2011).

\section{Gestão de Sistemas Integrados}

A Gestão da informação refere-se ao conhecimento que pode ser coletado, processado e administrado, por isso foi incorporada às amplas questões que a gestão do conhecimento compreende (SILVA, 2007).

Toumi (2001) aborda que o sucesso do negócio esta ficando cada vez mais dependente da inovação e do conhecimento, que estão mudando as formas tradicionais de organizar negócios na empresa.

$\mathrm{Na}$ abordagem de Barclay e Murray (1997) a gestão do conhecimento enfatiza aspectos culturais e de redefinição de processos. Assim Vick et al. (2009) destaca a relação de dependência da informação e o ambiente, cujo significado esta ligado ao sistema em que esta incorporada. A informação é o único recurso que não se perde com o uso ou com a disseminação, a mesma só se perde quando se torna obsoleta.

A Gestão da Informação resume-se em etapas. São estas: dados, informação e sistema de informação. Dados são fatos que não passaram por nenhum processamento, estão em sua forma bruta, precisam, portanto, ser analisados para se extrair alguma informação. Como isso, pode-se afirmar que o sistema de informação transforma os dados em informação.

A informação, assim como qualquer outro recurso organizacional - financeiro, material e humana - é um recurso que necessita ser gerenciado (AMORIM; TOMAÉL, 2011).

\section{Gestão do Produto}

Com a evolução da tecnologia, a criação de novos produtos se tornou motivo de competição entre as empresas, a organização que planeja e implementa uma nova concepção de produto certamente se tornará líder do seu setor. A gestão de produtos de uma organização esta inteiramente relacionada á estratégia de inovação tecnológica traçada por cada empresa.

As instituições estão conscientes que o sucesso depende da forma como estas projetam seus produtos e da habilidade de organização, de processamento e aprendizado. Segundo Naveiro (2005), a palavra projetar esta relacionada a uma atividade que produz uma descrição de algo que não existe, porém capaz de viabilizar a construção desse produto.

Bethlem (1999) explica que os produtos têm uma vida composta por ciclos, que vão do nascimento à morte. A Figura 2 ilustra o ciclo que contem quatro fases: Introdução, Crescimento, Maturidade e Declínio.

A primeira fase, denominada de introdução é na maioria das vezes um produto/serviço novo que poucos concorrentes oferecem. Nesta fase as necessidades dos clientes ainda não são bem compreendidas pela empresa. A segunda fase é caracterizada como estágio de crescimento, é nessa fase que os concorrentes começam a entrar no mercado, fazendo que a função produção acompanhe a demanda. O estágio de maturidade ocorre quando a demanda se estabiliza, o mercado é denominado por poucas empresas, sendo que algumas já se retiraram. A última fase é considerada de declínio, nesta etapa os concorrentes diminuirão e as vendas diminuíram até cessar. 


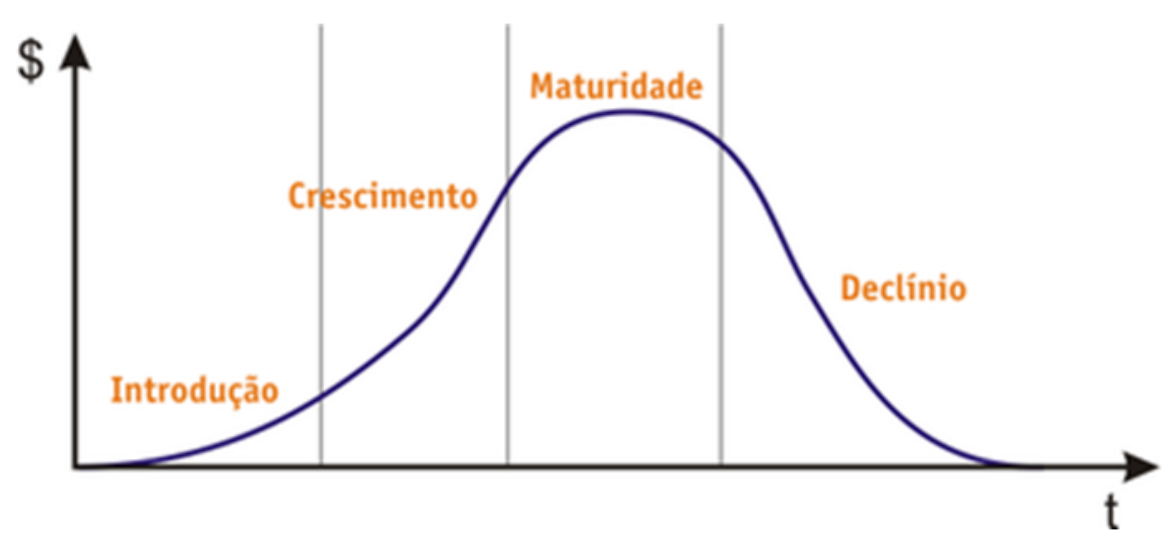

Figura 2: Curva do ciclo de vida do produto. Fonte: Adaptado de Bethlem , 1999.

\section{Gestão Financeira}

Em um cenário de competição acirrada gerir adequadamente custos e receitas é fator primordial para a sobrevivência de uma empresa, afirmar-se que todas as decisões tomadas por uma organização envolvem aspectos financeiros, com isso um bom gerenciamento dos custos de uma empresa gera a não falência da mesma. Para Bornia (2008), é importante que uma empresa conheça os seus vários custos para que seus investimentos possam ser avaliados e principalmente para se analisar a rentabilidade de uma empresa.

A gestão financeira relaciona todas essas características, dentre outras, intencionando uma melhor eficiência econômica relacionada aos fatores de produção, para que assim os lucros da empresa possam ser sempre crescentes ou estáveis.

\section{Gestão Estratégica}

É necessário que todas as ações de uma empresa, internas ou externas, sejam devidamente planejadas de acordo com os objetivos da organização. É através desse planejamento que a empresa poderá elaborar sua estratégia competitiva e, entendendo claramente seus objetivos, poderá estabelecer metas de acordo com a sua direção competitiva determinada. Slack (2009) afirma que após a empresa entender o seu papel dentro do negócio e estabelecer seus objetivos de desempenho, é preciso que esta formule um conjunto de princípios gerais que irão guiar as tomadas de decisões, princípios estes que influenciem a direção de longo prazo da empresa.

Para esse mesmo autor, as decisões estratégicas elucidam: o efeito abrangente na organização a qual a estratégia se refere; a definição da posição da organização relativamente a seu ambiente; a aproximação da organização perante seus objetivos de longo prazo.

\section{Gestão Logística}

Logística é uma atividade muito antiga, porem a implementação de melhores práticas tornou-se uma das áreas operacionais mais desafiantes da atualidade. Christopher (2002, p.02) define logística como: " o processo de gerenciar estrategicamente a aquisição, movimentação e armazenagem de materiais, peças e produtos acabados (e os fluxos de informações correlatas) através da organização e seus canais de marketing, de modo a poder maximizar as lucratividades atual e futura através do atendimento dos pedidos a baixo custo."

A logística é uma estratégica de competitividade adotada por diversas empresas e esta relacionada a redução de custos diante do fluxo de materiais e informações do processo logístico. 
Assim como todos os outros indicadores do SIMAP a logística também precisa ser bem gerida para trazer benefícios à corporação.

A gestão logística refere-se também à integração de todas as atividades associadas com a transformação e o fluxo de bens e serviços, desde as empresas fornecedoras de matéria-prima até o usuário final incluindo o fluxo de informação necessário para o sucesso (BALLOU et al. 2000).

O objetivo é que cada membro desempenhe as tarefas relacionadas à sua competência central, evitando-se desperdícios e funções duplicadas, facilitando o gerenciamento holístico que permite aproveitar as sinergias produzidas (POIRIER, 2001). Isso aumenta o compartilhamento de informação que vai além de dados sobre transações de compra e venda, incluindo aspectos estratégicos orientados ao planejamento conjunto, essenciais para permitir que as empresas participantes façam o que é certo de maneira mais rápida e eficiente (BOWERSOX e CLOSS, 2001).

\section{METODOLOGIA}

Esse trabalho possui uma abordagem qualitativa do problema, que de acordo com Diehl e Tatim (2004, p. 52):

\footnotetext{
"descreve a complexidade de determinado problema e a interação de certas variáveis, compreender e classificar os processos dinâmicos vividos por grupos sociais, contribuir no processo de mudança de dado grupo e possibilitar, em maior nível de profundidade, um entendimento das particularidades do comportamento dos indivíduos".
}

A partir desta abordagem, pode-se interagir da melhor forma com o grupo de funcionários para a obtenção dos dados mais realistas, o que foi de fundamental importância para esse trabalho.

A pesquisa abordada neste artigo é do tipo explicativa, a qual segundo Andrade (2005, p. 125) "além de registrar, analisar e interpretar os fenômenos estudados, procura identificar seus fatores determinantes, ou seja, suas causas".

Para essa pesquisa foram utilizados questionários semiestruturados, os quais apresentaram questões fechadas, que segundo Gil (1999, p. 129) "apresenta-se ao respondente um conjunto de alternativas de respostas para que seja escolhida a que melhor representa sua situação ou ponto de vista", e aberta que ainda para esse autor, "apresenta-se a pergunta e deixa-se um espaço em branco para que a pessoa escreva sua resposta sem qualquer restrição".

As informações obtidas através do questionário semiestruturado foram alocadas no SIMAP e os critérios de desempenho analisados estão apresentados no ANEXO A. Os dados foram analisados e os gráficos foram desenvolvidos com o auxilio do SIMAP com o intuito de melhor comparar os indicadores das empresas analisadas.

A acessibilidade aos dados é crucial para o sucesso de uma pesquisa. Gil (1999, p. 104) elucida: "o pesquisador seleciona os elementos a que tem acesso". Assim a amostragem da pesquisa contou com duas empresas da cadeia de alimentos e bebidas, das quais uma atua internacionalmente e outra apenas regionalmente.

Os dados coletados nas empresas foram transformados em informações. Essas informações foram encaminhadas para as empresas analisadas, as quais puderam verificar pontos forte e fracos, possibilitando melhorias nos seus processos de gestão. 


\section{ESTUDO DE CASO}

\section{Empresa Pittsburg}

O Pittsburg iniciou suas atividades voltadas ao segmento fastfood em 1984 e conta atualmente com 12 lojas em três cidades diferentes. A empresa tem como missão: "oferecer sempre os produtos mais gostosos, um ambiente muito agradável e um atendimento de altíssima qualidade prestado por uma equipe motivada, satisfazendo e surpreendendo os nossos clientes e colaboradores e contribuindo para o crescimento do país" (PITTSBURG, 2013). A empresa faz parte do arranjo de cadeia de alimentos e bebidas, integrando assim o elo de comércio e vendas. Atualmente possui um faturamento da ordem de $\mathrm{R} \$ 1$ milhão anual, atingindo um mercado regional (Rio Grande do Norte) e com cerca de 100 empregados, sendo que nenhum deles possui mestrado, especialização ou doutorado.

Através de seus processos produtivos, esta empresa busca acima de tudo, fornecer produtos de boa qualidade além de uma preocupação ambiental no desenvolvimento de produtos que gerem poucos resíduos. Dentre as principais tecnologias empregadas pela empresa destaca-se a utilização do Girassol e Colibri, sistema utilizado na gestão da empresa, que auxilia diretamente nas decisões tomadas como também de todo o controle da produção.

\section{Empresa McDonald's}

O McDonald's é líder no segmento de serviço rápido de alimentação e esta presente em 119 países, possuindo 33 mil restaurantes, onde trabalham 1,7 milhão de colaboradores. No Brasil a rede opera desde 1979 com sua primeira loja no Estado do Rio de Janeiro. Em 2010 a empresa já contava com 600 lojas no território nacional (McDonald's, 2013).

A empresa tem como missão: Servir comida de qualidade, proporcionando sempre uma experiência extraordinária (McDonald's, 2013). No SIMAP, a empresa pertence à cadeia de alimentos e bebidas, participando do elo de comércio e mercado e a unidade pesquisada da empresa situa-se na Avenida Prudente de Moraes na cidade de Natal/RN.

A empresa preza: pelo atendimento diferencial, requisito da empresa líder; produtos de qualidade com velocidade, requisito do setor; e qualidade e velocidade para os requisitos de competitividade global.

\section{DISCUSSÃO DOS RESULTADOS}

\section{Empresa Pittsburg}

Surpreendentemente, nos requisitos de sistema de gestão integrada, a empresa possui apenas procedimentos formais na ISO 9001 e 5S, enquanto no que diz respeito a ISO 14001, SA 8000 e OSHAS 18000 a empresa afirmou apenas que possui sistemas equivalentes, informais, e que não são realizados com frequência tais controles.

Quanto ao sistema de gestão de produção, a empresa obteve pontuação média em praticamente todos os quesitos, destacando-se PCP, Desenvolvimento dos Fornecedores e Idade Média dos Equipamentos, respectivamente possuindo ERP (sistema de gestão integrado), construindo parcerias com seus fornecedores e possuindo equipamentos relativamente novos, com menos de cinco anos de utilização. 
De maneira geral, o sistema de gestão estratégica da empresa se destaca por conseguir obter pontuação máxima em quase todos os quesitos, como planejamento estratégico, planos de ações, etc., exceto na utilização de benchmarking e a utilização de indicadores, mostrando o perfil de uma empresa que busca adaptar suas missões, valores, e conceitos de acordo com a situação atual do mercado em que atua, mesmo não utilizando para tomar suas decisões fatores importantes como indicadores e dados comparativos com concorrentes, o qual é feita apenas de maneira visual, através de visitas feitas pelos gerentes e funcionários da empresa em seus concorrentes.

A empresa relata através dos seus dados, um perfil ainda em crescimento em gestão logística. Obteve cerca de vinte e cinco pontos nos índices, tais como: fluxo de informação, fluxo financeiro. Já nas transações comerciais, a empresa utiliza apenas e-mail ou telefones para realizar a comunicação, deixando de utilizar ferramentas mais precisas e que possam fornecer dados mais completos.

Obteve destaque a rotatividade de estoque, o qual por se tratar de uma empresa no ramo alimentício, possui uma rotatividade geral superior a 24 giros/ano. Quanto à obtenção das matérias primas, a empresa possui serviço terceirizado para o mesmo, o que não deixa de lado ferramentas de transporte interno que muitas vezes são obtidos através da sede na cidade de Natal.

Na gestão de recursos humanos, a Pittsburg possui plano de treinamento superior a 20 horas, vários programas participativos para seus funcionários e a descrição de cargos e competências são feita de um programa de multifuncionalidade.

No sistema de gestão financeira, a empresa possui pontuação máxima em todos os quesitos, o que nos mostra uma maior qualidade no tratamento destes dados, servindo como base na tomada de decisão em praticamente todos os setores, utilizando o sistema ERP integrado, Custeio Direto, Curva ABC e método de Análise de Investimento como ferramentas de auxilio.

A Figura 3 ilustra a situação da empresa Pisttsburg em relação à média de todas as empresas cadastradas no SIMAP pertencentes à cadeia produtiva em estudo.

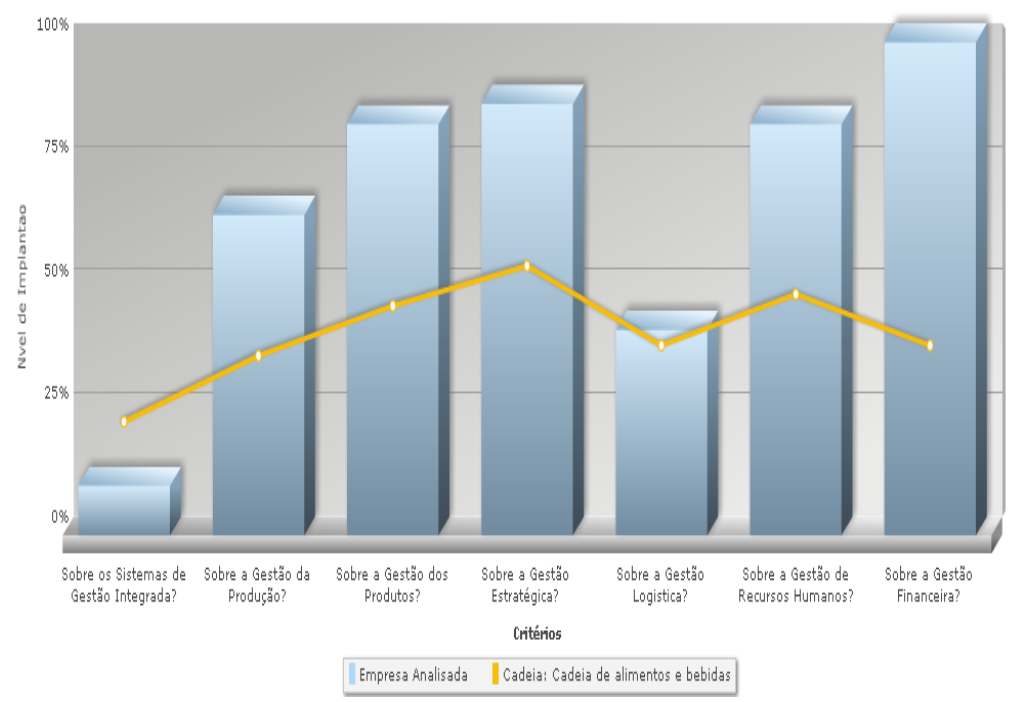

Figura 3: Comparação entre a empresa Pittsburg e empresas da cadeia de alimentos e bebidas. Fonte: SIMAP (2010). 
Percebe-se que a empresa Pittsburg deve desenvolver sua gestão integrada, pois esta bem abaixo da média das empresas pertencentes à cadeia na qual esta inserida.

\section{Empresa McDonald's}

Dentre as principais tecnologias empregadas pela empresa destaca-se a utilização do SIC sistema integrado de Comunicação, sendo seu principal desafio para os próximos anos o desenvolvimento de novos produtos e a expansão no mercado. Com relação aos sistemas de gestão integrada, verificou-se que a empresa possui a certificação ISO 9001, fato este esperado por se tratar de uma empresa mundialmente reconhecida no ramo de alimentos, porém esta ainda não adquiriu certificações importantes como: ISO 14000, 5S, AS 8000, OSHAS 18000, sendo apenas os conceitos implementados pela empresa.

No que tange à gestão da produção, afirma-se que a organização possui desempenho satisfatório, fato este comprovado pela sua máxima pontuação em quesitos fundamentais da produção, sendo eles: planejamento e controle da produção, controle de processos, defeitos PPM, manutenção corretiva-preventiva, uso de ferramentas Just in time, desenvolvimento dos fornecedores e idade média dos equipamentos.

A gestão dos produtos obteve desempenho satisfatório, evidenciado pela alta pontuação em questões chaves desta gestão, como: domínio e uso de normas técnicas, uso de engenharia simultânea e equipamentos multifuncionais; uso de tecnologia para desenvolvimento de novos produtos, destaca-se a criação da universidade do hambúrguer, instituição desenvolvida com a finalidade do estudo e desenvolvimento de novos produtos.

Sobre a gestão estratégica, a empresa possui desempenho superior a todas as outras áreas em questão, pois esta conseguiu pontuação máxima em todos os quesitos, sendo eles: realização de planejamento estratégico, plano de atuação na estratégia de produção, ambiente para melhoria no estilo de liderança e envolvimento dos empregados, uso de benchmarking, clientes satisfeitos, e a utilização do PDCA como indicador.

Referindo-se a gestão logística, o McDonald's possui desempenho mediano. Apesar de apresentar itens com pontuação máxima, itens estes fundamentais, como: controle de estoque gerenciado por um sistema integrado de gerenciamento de estoque, giro de estoque maior que 24 giros/ano, integração total no fluxo financeiro, e parcerias estratégicas no relacionamento da cadeia de suprimentos. O desempenho da utilização de muitas máquinas com interferência humana, controle de armazém e as transações comerciais feitas apenas por computador apresentou pontuação de 25 .

$\mathrm{Na}$ área de recursos humanos as questões analisadas foram: plano de treinamento, descrição de cargos e competências, e programas participativos. A organização em questão obteve plano de treinamento superior a 20 horas, sistema de avaliação de competências e participação dos funcionários nos resultados da empresa. Este fato demonstra a preocupação da empresa no treinamento e capacitação de seus colaboradores.

O último quesito explorado diz respeito à gestão de finanças. A empresa não realiza formalmente ferramentas como custeio direto e curva $A B C$, porém baseia suas tomadas de decisões em um ERP integrado e em um método de análise de investimento.

A Figura 4 demonstra a situação da empresa McDonald's em relação à média de todas as empresas cadastradas no SIMAP pertencentes à cadeia produtiva em estudo. 


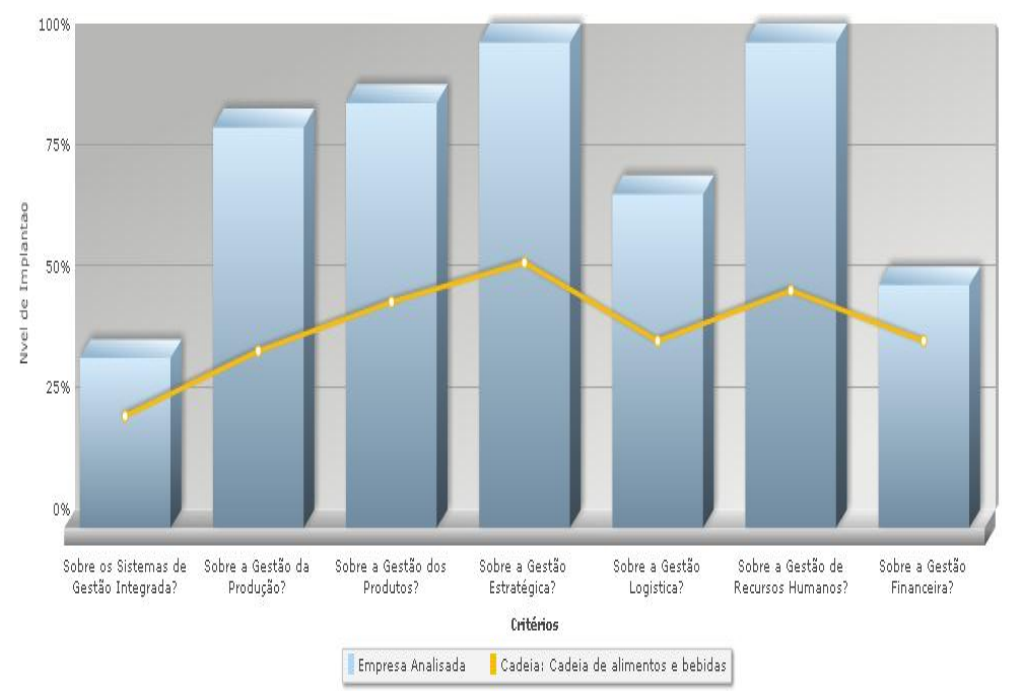

Figura 4: Comparação entre a empresa McDonald's e empresas da cadeia de alimentos e bebidas. Fonte: SIMAP (2010).

Por intermédio da Figura 4, consegue-se visualizar forte atuação da empresa em gestão estratégica, justificando sua posição como líder na cadeia produtiva de alimentos e bebidas.

A Figura 5 traz a comparação direta entre as empresas estudadas.

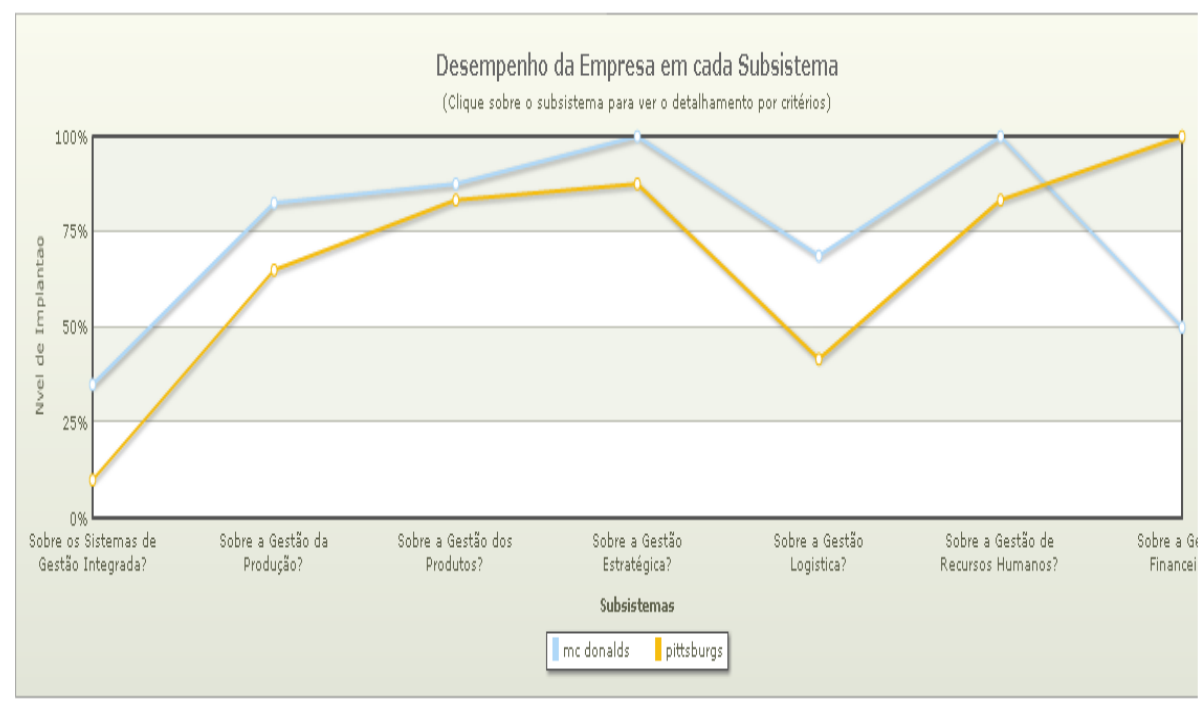

Figura 5: Comparação entre a empresa McDonald's e Pittsburg. Fonte: SIMAP (2010).

Por intermédio da figura 5 verifica-se que a empresa McDonald's esta com pontuação acima da empresa Pittsburg em quase todos os indicadores, porém a segunda empresa foi superior na Gestão Financeira, onde esta pontuou $100 \%$ e a sua concorrente $50 \%$.

As empresas obtiveram suas piores pontuações em Sistema de Gestão Integrada, ficando evidente a falta de preocupação das empresas em conseguir certificações do processo. Para as empresas, a implantação de ações em alguns pontos é suficiente para seu processo.

$O$ indicador Gestão do Produto demonstrou maior semelhança entre as empresas pesquisadas, apresentando uma diferença entre elas de apenas $4 \%$. A criação de novos produtos é observada como um diferencial perante a concorrência e por isto obteve pontuações altas em ambas as empresas. 


\section{CONSIDERAÇÕES FINAIS}

A utilização do SIMAP como ferramenta de benchmarking para empresas da cadeia produtiva estudada é de extrema importância, pois as empresas podem verificar sua atual posição perante as outras empresas, verificar e desenvolver os pontos fracos da organização visando obter o diferencial competitivo para se manterem no mercado.

Através deste estudo, chega-se a afirmativa no que se refere à importância de se conhecer a cadeia produtiva, analisando todos os fatores que possam agregar valor ao produto oferecido pela empresa.

Ressalta-se a relevância do trabalho no que tange a comparação de duas empresas de fastfood, sendo uma de referência mundial e a outra regional. Com a devida análise dos gráficos do SIMAP, percebem-se algumas peculiaridades inerentes às duas empresas estudadas, porem chega-se a assertiva que a empresa McDonald's, obteve uma leve vantagem em relação à empresa Pittsburg, porem a empresa em desvantagem já identificou os pontos fracos e pode facilmente trabalhar para alcançar o líder de mercado no Estado do Rio Grande do Norte.

Verificou-se que as empresas estudadas estão em conformidade com os requisitos dos seus clientes, buscando sempre a satisfazê-los. Observou-se também que cinco dos sete indicadores do SIMAP estudados na empresa Pittsburg estão acima da média da cadeia produtiva estudada e que todos os indicadores da empresa McDonald's ficarão acima da média da cadeia produtiva estudada. Isto é justificado, pois a empresa McDonald's é o líder de mercado nesta cadeia.

O estudo também servirá de base para novos trabalhos a serem desenvolvidos na cadeia de alimentos e bebidas, servindo de fonte de informação para alcançar novos diferenciais competitivos e consequentemente novos mercados.

\section{REFERÊNCIAS BIBLIOGRÁFICAS}

ALBERTIN, M; et al. Sistemas de Benchmarking através da Internet - SIMAP: Histórico, características, benefícios e lições aprendidas. VI Simpósio de Sistemas de Informação e Engenharia de Produção, 2010.

ALVARENGA_NETO, R. C. D. D. Gestão do conhecimento em organizações: Proposta de mapeamento conceitual integrativo. Programa de Pós-Graduação em Ciências da Informação, Universidade Federal de Minas Gerais, Belo Horizonte, 400 p., 2005.

AMATO NETO, J. Gestão de Sistemas Locais de Produção e Inovação (CLUSTERS/APLs): um modelo de referência. São Paulo: atlas, v.1. 2009.

AMORIN, F.B; TOMAÉL, M.I. Gestão da informação e gestão do conhecimento na prática organizacional: análise de estudos de casos. Revista Digital de Biblioteconomia e Ciência da Informação. Campinas. v. 8, n. 2, p. 01-22, 2011.

ANDRADE, M.M. Introdução à metodologia do trabalho científico: elaboração de trabalhos na graduação. 7. Ed. São Paulo: Atlas, 2005.

AQUINO, C; PINHEIRO, E. Programa de desenvolvimento de distritos industriais: uma experiência de internacionalização de APLs. Brasília: SEBRAE, 2006. 
ARAUJO, L.C.G. Organização, sistemas e métodos e as modernas ferramentas de gestão organizacional. São Paulo: Atlas, 2001.

BALLOU, R. H.; GILBERT, S. M.; MUKHERJEE, A. New Managerial Challenges from Supply Chain Opportunities. Industrial Marketing Management. 29, p.7-18, 2000.

BARCLAY, R. U.; MURRAY, P. What is knowledge management. A Knowledge praxis. [S. I. : s. n.], . p. 51-83, 1997.

BETHLEM, A. Estratégia Empresarial: Conceitos, Processo e Administração Estratégica. 2. ed. São Paulo: Atlas, 1999.

BNDES, BANCO NACIONAL DE DESENVOLVIMENTO ECONOMICO E SOCIAL. Notícias. Disponível em: http://www.bndes.gov.br/noticias/not620.asp Acesso em: 15 nov 2010.

BORNIA, A.C. Introdução a Engenharia de Produção. Rio de Janeiro: Campus Elsevier, 2008.

BOWERSOX, D. J.; CLOSS, D. J. Logística Empresarial: O Processo de Integração da Cadeia de Suprimento. São Paulo: Editora Atlas, 2001.

CAMP, R.C. Benchmarking: o caminho a qualidade total. São Paulo. Pioneira, 1998.

CHRISTOPHER, M. Logística e gerenciamento da cadeia de suprimentos. São Paulo: Pioneira Thomson, 2002.

DIEHL, A; TATIM, D. C. Pesquisa em ciências sociais aplicadas. São Paulo: Pearson Prentice Hall, 2004.

ENRIGHT, M. Regional clusters and firms strategy. The Dynamic Firm: The Role of Technology, Strategy, Organization, and Regions: Oxford University Press. Regional clusters and firms strategy, p.315-343, 1999.

GARCIA, M. M. A; FERNANDES, M.T.M. A revolução alimentar: Da cozinha ao Fastfoods. In: XIV Encontro Latino Americano de Iniciação Científica INIC; $X$ Encontro Latino Americano de Pós Graduação EPG e IV Encontro Latino Americano de Iniciação Científica Junior INIC Jr., São José dos Campos/SP, 2010.

GARIBA JUNIOR, M. Um modelo de avaliação de cursos superiores de tecnologia baseado na ferramenta Benchmarking. Tese Doutorado em Engenharia de Produção, Universidade Federal de Santa Catarina, Florianópolis, 2005

GIL, Antônio Carlos. Método e técnica de pesquisa social. 2. Ed. São Paulo: Atlas, 1999.

HÉKIS, H. R.; QUEIROZ, J. V.; SOUZA, R. P.; HÉKIS, L. G. R.; OLIVEIRA, L. A. B. Gestão de Custos: A importancia da Utilização desta ferramenta em uma unidade educacional. CEPPG Revista (Catalão), v. 24, p. 34-58, 2011.

JOHNSON, A. M., et al. Large-scale Internet benchmarking: Technology and application in warehousing operations. Computers in Industry_v.61, p.280-286, 2010.

MCDONALD'S. Sobre o McDonald's. Disponível em: http://www.mcdonalds.com.br/. Acesso em: Março/2013.

MOREIRA, D. A. Administração da Produção e Operações. 5. Ed. São Paulo: Pioneira, 2000. 
NAVEIRO, D. M. Adding consumer knowledge to product development process. In: 18th International Conference on Production Research, 2005, Salerno. Anais do 18th International Conference on Production Research, 2005.

OBSERVATÓRIO TECNOLÓGICO. Disponível em: www.ot.ufc.br. Acesso em Jan/2012

PAULINO, F.O. Produção e Características de Qualidade de Hamburguer de Carne de Jacaré-doPantanal. Tese de Doutorado. Universidade Federal Fluminense, 2012.

PITTSBURG. Sobre o Pittsbrug. Disponível em: http://www.pittsburg.com.br /noticias/institucional/sobreopitts. Acesso em: Março/2013.

POIRIER, C. C. Administración de cadenas de aprovisionamento. Cómo construir una ventaja competitiva sostenida. México: Oxford University Press, 2001.

PORTER, M. E. Competição - On Competition: Estratégias Competitivas Essenciais. Rio de Janeiro: Campus Elsevier. 1999. 520 p.

QUEIROZ, F. C. B. P. HÉKIS, H. R. QUEIROZ, J. V. A geração de inovação como estratégia de diferenciação: Um estudo com empresas do setor de tintas, vernizes e solventes do sul de Santa Catarina. Revista CEPPG - CESUC - Centro de Ensino Superior de Catalão, Ano XIII, № 23, 2010.

SILVA, T.E. A Gestão da Informação nas Organizações. Revista Informação \& Informação. v.12, n.2, 2007.

SIMAP. Sistema de Monitoramento de Arranjos Produtivos. Disponível em: http://www.ot.ufc.br/portal02/index.php?option=com_content\&task=view\&id=55\&ltemid=56. Acesso em Dez/2010.

SLACK, N.; CHAMBERS, S.; JOHNSTON, R.. Administração da Produção. 3. Ed.São Paulo: Atlas, 2009.

TOUMI, I. From periphery to center: emerging research topics on knowledge society. Technology Review, Helsinki, v. 16, p. 1-63, 2001.

VICK, T., M. S. NAGANO, et al. Aportes da gestão da informação para a criação de conhecimento em equipes de inovação. Perspectivas em Ciência da Informação, v.14, n.2, p.204-219, 2009.

\section{ANEXO A - Critérios de Desempenho do SIMAP}

SIG: Sistema integrado de Gestão

\begin{tabular}{|l|c|c|c|c|c|}
\hline \multicolumn{1}{|c|}{ SIG } & $\mathbf{0}$ & $\mathbf{2 5}$ & $\mathbf{5 0}$ & $\mathbf{7 5}$ & $\mathbf{1 0 0}$ \\
\hline ISO 9001 & $\begin{array}{c}\text { Procedimentos } \\
\text { informais }\end{array}$ & $\begin{array}{c}\text { Procedimentos } \\
\text { documentados } 14001\end{array}$ & $\begin{array}{c}\text { Programa formal } \\
\text { de implantação }\end{array}$ & $\begin{array}{c}\text { Realiza auditorias } \\
\text { internas }\end{array}$ & Certificação \\
5S & & & & & \\
SA8000 & & & & \\
OSHAS18000 & & & & \\
\hline
\end{tabular}

Gestão Financeira

\begin{tabular}{|c|c|c|c|c|c|}
\hline & 0 & 25 & 50 & 75 & 100 \\
\hline $\begin{array}{l}\text { ERP; } \\
\text { Custeio Direto; } \\
\text { Custeio ABC; } \\
\text { Método de análise } \\
\text { de investimento. }\end{array}$ & $\begin{array}{l}\text { Não realiza } \\
\text { formalmente }\end{array}$ & Implementando & Realiza parcialmente & $\begin{array}{l}\text { Fase final de } \\
\text { implementação. }\end{array}$ & $\begin{array}{l}\text { Utiliza para } \\
\text { tomada de } \\
\text { decisões }\end{array}$ \\
\hline
\end{tabular}


Gestão Estratégica

\begin{tabular}{|c|c|c|c|c|c|}
\hline & 0 & 25 & 50 & 75 & 100 \\
\hline $\begin{array}{l}\text { Planejamento } \\
\text { estratégico }\end{array}$ & Informal & Formal & $\begin{array}{c}\text { Monitora } \\
\text { periodicamente }\end{array}$ & Informa a todos & $\begin{array}{l}\text { Desdobra missão, } \\
\text { visão e indicadores } \\
\text { (ex. BSC). }\end{array}$ \\
\hline $\begin{array}{l}\text { Estratégia de } \\
\text { produção }\end{array}$ & Informal & Definida & Monitora & Informa & Plano de ação \\
\hline $\begin{array}{l}\text { Estilo de liderança e } \\
\text { envolvimento dos } \\
\text { empregados }\end{array}$ & Controlador & Centralizado & Descentralizado & Participativo & $\begin{array}{c}\text { Ambiente para } \\
\text { melhoria }\end{array}$ \\
\hline $\begin{array}{l}\text { Uso do } \\
\text { Benchmarking }\end{array}$ & Não utiliza & Benchmarking local & $\begin{array}{l}\text { Benchmarking } \\
\text { regional }\end{array}$ & $\begin{array}{c}\text { Benchmarking } \\
\text { nacional }\end{array}$ & $\begin{array}{l}\text { Benchmarking } \\
\text { internacional }\end{array}$ \\
\hline Orientação ao cliente & Informal & $\begin{array}{c}\text { Monitora } \\
\text { insatisfação }\end{array}$ & $\begin{array}{l}\text { Pesquisa de } \\
\text { satisfação }\end{array}$ & $\begin{array}{l}\text { Monitora a } \\
\text { satisfação }\end{array}$ & $\begin{array}{l}\text { Cliente - muito } \\
\text { satisfeito > } 80 \%\end{array}$ \\
\hline Indicadores & Informal & Financeiros & Qualidade & Processos & $\begin{array}{c}\text { PDCA - Metas } \\
\text { definidas }\end{array}$ \\
\hline
\end{tabular}

Gestão de Produtos

\begin{tabular}{|c|c|c|c|c|c|}
\hline & 0 & 25 & 50 & 75 & 100 \\
\hline $\begin{array}{l}\text { Domínio e uso de } \\
\text { normas técnicas }\end{array}$ & Desconhece & $\begin{array}{l}\text { Conhece e utiliza } \\
\text { parcialmente }\end{array}$ & Utiliza as principais & Utiliza sempre & $\begin{array}{c}\text { Utiliza } 100 \% \text { e } \\
\text { atualiza }\end{array}$ \\
\hline CAD - CAE - CIM & Desconhece & Conhece & Utiliza CAD & CAD e CAE & CAD-CAE-CIM \\
\hline $\begin{array}{l}\text { Uso de Eng. } \\
\text { Simultânea e Equipes } \\
\text { Multifuncionais }\end{array}$ & Não utiliza & $\begin{array}{c}\text { Utiliza } \\
\text { informalmente }\end{array}$ & $\begin{array}{l}\text { Procedimento } \\
\text { documentado }\end{array}$ & Implementando & Utiliza sempre \\
\hline $\begin{array}{l}\text { Lead Time de } \\
\text { desenvolvimento }\end{array}$ & Não controla & Controle informal & Monitora & Competitivo & É benchmark \\
\hline $\begin{array}{l}\text { Metodologia para } \\
\text { desenvolvimento }\end{array}$ & Desconhece & Informal & Documentado & $\begin{array}{c}\text { Melhora } \\
\text { continuamente }\end{array}$ & $\begin{array}{l}\text { Usa conceito } \\
\text { lessons learn }\end{array}$ \\
\hline $\begin{array}{l}\text { Parcerias com } \\
\text { Fornecedores/ } \\
\text { Clientes }\end{array}$ & Não realiza & Informal & Formal & Fornecedores & $\begin{array}{l}\text { Fornecedores e } \\
\text { clientes }\end{array}$ \\
\hline
\end{tabular}

\section{Gestão da Produção}

\begin{tabular}{|c|c|c|c|c|c|}
\hline & 0 & 25 & 50 & 75 & 100 \\
\hline $\begin{array}{l}\text { Tempo de setup } \\
\text { (médio da fábrica) }\end{array}$ & Informal & $\begin{array}{l}\text { Procedimento } \\
\text { documentado }\end{array}$ & Tempo $<60 \mathrm{~min}$ & Tempo $<40 \mathrm{~min}$ & $<10$ (SMED) \\
\hline PCP & Informal & $\begin{array}{l}\text { Planilhas eletrônicas } \\
\text { (Excel, Calc, etc.). }\end{array}$ & Software & MRP e MRP II & ERP \\
\hline $\begin{array}{l}\text { Estudos de } \\
\text { Capabilidade }\end{array}$ & Informal & Processos instáveis & $\begin{array}{l}\text { Processos } \\
\text { estáveis }\end{array}$ & CEP & Cpk $>2$ \\
\hline $\begin{array}{l}\text { Custos da (má) } \\
\text { Qualidade }\end{array}$ & Desconhecidos & Monitora & $\begin{array}{c}1-10 \% \\
\text { faturamento }\end{array}$ & $<1 \%$ faturamento & $\begin{array}{c}<<0,5 \\
\text { faturamento }\end{array}$ \\
\hline $\begin{array}{l}\text { Controle de } \\
\text { processos }\end{array}$ & $\begin{array}{l}\text { Parâmetros } \\
\text { informais }\end{array}$ & Parâmetros formais & $\begin{array}{l}\text { Parâmetros } \\
\text { controlados }\end{array}$ & $\begin{array}{c}\text { Instrumentos } \\
\text { calibrados }\end{array}$ & $\begin{array}{c}\text { Estudos de } \\
\text { Capabilidade }\end{array}$ \\
\hline Defeitos - PPM & Desconhecidos & Conhecidos & $1-10 \%$ & $<1000 \mathrm{ppm}$ & $<500 \mathrm{ppm}$ \\
\hline Manutenção & Corretiva & $\begin{array}{c}\text { Plano de } \\
\text { manutenção informal }\end{array}$ & Preventiva & Preditiva & TPM \\
\hline $\begin{array}{l}\text { Filosofia e } \\
\text { Ferramentas JIT }\end{array}$ & $\begin{array}{l}\text { Não utiliza } \\
\text { ferramentas }\end{array}$ & Uma ferramenta & Duas ferramentas & Três ferramentas & $\begin{array}{c}\text { Muitas } \\
\text { ferramentas }\end{array}$ \\
\hline $\begin{array}{l}\text { Desenvolvimento de } \\
\text { Fornecedores }\end{array}$ & Informal & Formal & $\begin{array}{c}\text { Monitora } \\
\text { desempenho }\end{array}$ & $\begin{array}{c}\text { Programas de } \\
\text { capacitação }\end{array}$ & $\begin{array}{l}\text { Estabelece } \\
\text { parcerias }\end{array}$ \\
\hline $\begin{array}{l}\text { Idade média dos } \\
\text { equipamentos }\end{array}$ & Desconhecida & Maior de 20 anos & 10 a 20 anos & 5 a 10 anos & $<5$ anos \\
\hline
\end{tabular}




\section{Gestão da Logística}

\begin{tabular}{|c|c|c|c|c|c|}
\hline & 0 & 25 & 50 & 75 & 100 \\
\hline Fluxo de materiais & $\begin{array}{c}\text { Manual, Controle } \\
\text { Visual }\end{array}$ & $\begin{array}{c}\text { Planilha } \\
\text { eletrônica ou } \\
\text { softwares }\end{array}$ & $\begin{array}{l}\text { Uso de código } \\
\text { de barras }\end{array}$ & $\begin{array}{l}\text { RFID } \\
\text { GPS }\end{array}$ & $\begin{array}{l}\text { Container } \\
\text { Inteligente }\end{array}$ \\
\hline $\begin{array}{l}\text { Fluxo de } \\
\text { Informação }\end{array}$ & $\begin{array}{l}\text { Consulta por } \\
\text { telefone celular }\end{array}$ & $\begin{array}{l}\text { Consulta por } \\
\text { internet e } e \text { - } \\
\text { mail }\end{array}$ & EDI & $\begin{array}{c}\text { Rastreamento por } \\
\text { satélite ou GPRS }\end{array}$ & $\begin{array}{c}\text { Bases de dados } \\
\text { integradas na cadeia } \\
\text { de suprimento }\end{array}$ \\
\hline Fluxo Financeiro & Informal & Individual & $\begin{array}{l}\text { Parcialmente } \\
\text { Integrado }\end{array}$ & $\begin{array}{l}\text { Compartilhamento de } \\
\text { bancos de dados }\end{array}$ & Integração total \\
\hline $\begin{array}{l}\text { Transações } \\
\text { comerciais }\end{array}$ & Manual & $\begin{array}{l}\text { Pedidos } \\
\text { através do } \\
\text { computador }\end{array}$ & $\begin{array}{c}\text { RC } \\
\text { ou } \\
\text { VMI }\end{array}$ & $\begin{array}{l}\text { ECR } \\
\text { e } \\
\text { CRM }\end{array}$ & Marketplace \\
\hline $\begin{array}{l}\text { Controle de } \\
\text { armazém }\end{array}$ & $\begin{array}{c}\text { Manual ou } \\
\text { controle visual }\end{array}$ & $\begin{array}{c}\text { Planilha } \\
\text { eletrônica ou } \\
\text { software }\end{array}$ & $\begin{array}{l}\text { Uso de código } \\
\text { de barras }\end{array}$ & $\begin{array}{c}\text { Acompanhamento pelo } \\
\text { telefone celular ou Voz } \\
\text { de seleção ou RFID }\end{array}$ & $\begin{array}{c}\text { Sistema de } \\
\text { Gerenciamento de } \\
\text { Armazém (WMS) }\end{array}$ \\
\hline $\begin{array}{l}\text { Sistema de } \\
\text { Transportes }\end{array}$ & Informal & $\begin{array}{l}\text { Planilha } \\
\text { eletrônica ou } \\
\text { software }\end{array}$ & Milk-run & $\begin{array}{l}\text { GPS, Software de } \\
\text { roteamento. }\end{array}$ & $\begin{array}{c}\text { Sistema de } \\
\text { Gerenciamento dos } \\
\text { Transportes (TMS) }\end{array}$ \\
\hline $\begin{array}{l}\text { Relacionamento na } \\
\text { cadeia de } \\
\text { suprimento }\end{array}$ & $\begin{array}{l}\text { Curtos } \\
\text { relacionamentos }\end{array}$ & Parcerias & $\begin{array}{l}\text { Parcerias por } \\
\text { longos } \\
\text { períodos }\end{array}$ & $\begin{array}{l}\text { Gerenciamento do } \\
\text { relacionamento com } \\
\text { fornecedores }\end{array}$ & $\begin{array}{c}\text { Parcerias } \\
\text { estratégicas }\end{array}$ \\
\hline
\end{tabular}

\section{Gestão de Recursos Humanos}

\begin{tabular}{|c|c|c|c|c|c|}
\hline & 0 & 25 & 50 & 75 & 100 \\
\hline $\begin{array}{l}\text { Plano de } \\
\text { Treinamento }\end{array}$ & Informal & $\begin{array}{l}\text { Procedimento } \\
\text { documentado }\end{array}$ & $\begin{array}{c}\text { Monitora horas } \\
\text { treinamento ano/ } \\
\text { funcionário }\end{array}$ & $<20$ horas & $>20$ horas \\
\hline $\begin{array}{l}\text { Descrição de cargos } \\
\text { e competências }\end{array}$ & Informal & $\begin{array}{c}\text { Descrição de } \\
\text { responsabilidade/ } \\
\text { autoridade }\end{array}$ & $\begin{array}{l}\text { Descrição de } \\
\text { Competências }\end{array}$ & $\begin{array}{c}\text { Programa de } \\
\text { multifuncionalidade }\end{array}$ & $\begin{array}{l}\text { Avaliação de } \\
\text { competências }\end{array}$ \\
\hline $\begin{array}{l}\text { Programas } \\
\text { participativos }\end{array}$ & Informal & Formal & $\begin{array}{l}\text { Mais de um } \\
\text { programa }\end{array}$ & Vários programas & $\begin{array}{l}\text { Participação em } \\
\text { resultados }\end{array}$ \\
\hline
\end{tabular}

